\title{
Response surface methodology (RSM) and its application for optimization of ammonium ions removal from aqueous solutions by pumice as a natural and low cost adsorbent
}

\author{
Masoud Moradi ${ }^{1}$, Mehdi Fazlzadehdavil2 ${ }^{2}$, Meghdad Pirsaheb ${ }^{3}$, Yadollah Mansouri ${ }^{3}$, \\ Touba Khosravi ${ }^{3}$, Kiomars Sharafi ${ }^{3,4 *}$ \\ ${ }^{1}$ Iran University of Medical Sciences, Iran \\ School of Public Health, Department of Environmental Health Engineering \\ ${ }^{2}$ Ardabil University of Medical Sciences, Iran \\ School of Public Health, Department of Environmental Health Engineering \\ ${ }^{3}$ Kermanshah University of Medical Sciences, Iran \\ School of Public Health, Research Centre for Environmental Determinacies of Health \\ ${ }^{4}$ Tehran University of Medical Sciences, Iran \\ School of Public Health, Department of Environmental Health Engineering \\ ${ }^{*}$ Corresponding author's e-mail: kiomars.sharafi@gmail.com
}

Keywords: Pumice ammonium ion adsorption, response surface methodology.

\begin{abstract}
This research was conducted to study the adsorption of ammonium ions onto pumice as a natural and low-cost adsorbent. The physico-chemical properties of the pumice granular were characterized by X-ray diffraction (XRD), Fourier transforms infrared spectroscopy (FTIR) and scanning electron microscopy (SEM). Modeling and optimization of a $\mathrm{NH}_{4}^{+}$sorption process was accomplished by varying four independent parameters (pumice dosage, initial ammonium ion concentration, mixing rate and contact time) using a central composite design (CCD) under response surface methodology (RSM). The optimum conditions for maximum removal of $\mathrm{NH}_{4}^{+}(70.3 \%)$ were found to be $100 \mathrm{~g}, 20 \mathrm{mg} / \mathrm{l}, 300 \mathrm{rpm}$ and $180 \mathrm{~min}$, for pumice dosage, initial $\mathrm{NH}_{4}^{+}$ion concentration, mixing rate and contact time. It was found that the $\mathrm{NH}_{4}^{+}$adsorption on the pumice granular was dependent on adsorbent dosage and initial ammonium ion concentration. $\mathrm{NH}_{4}+$ was increased due to decrease the initial concentration of $\mathrm{NH}_{4}$ and increase the contact time, mixing rate and amount of adsorbent.
\end{abstract}

\section{Introduction}

The presence of nitrate and ammonium ions in effluents is a major concern due to their extreme toxicity, oxygen depletion in receiving water bodies and promotion of eutrophication (Arslan and Veli 2012). For these circumstances, it is necessary to develop efficient solutions to remove these pollutants from wastewater ensuring its reuse and/or decreasing the pollution to the acceptable standards for discharging into the receiving bodies of water.

There are several different approaches based on the mechanical and physicochemical methods for removing ammonium ions from wastewaters, such as biological nitrification-denitrification, chemical treatment, precipitation, air stripping, selective ion exchange and adsorption (Vassileva and Voikova 2009). Among these techniques, adsorption seems to be one of the economical and the most effective methods because of simple operation and easy handling (Akbal 2005, Khosravi et al. 2014, Pirsaheb et al. 2014). Adsorption is the most versatile process and widely used for the pollutants removal from wastewaters. Several types of ammonia adsorbents have been tested so far, but most of them remain on a laboratorialscale application (Bandosz and Petit 2009). In recent years, the treatment of the ammonia found in liquid or gaseous effluents by using adsorption onto activated carbon or other adsorbent material has been studied by several researchers.

Yuan and Kusuda (Yuan and Kusuda 2005) used a hydrogel of poly (N-isopropylacrylamide-co-chlorophyllin) to adsorb $\mathrm{NH}_{4}-\mathrm{N}$ and found that in a swollen state, the developed hydrogel had an adsorption capacity of $12.89 \mathrm{mg} / \mathrm{g}$ for $\mathrm{NH}_{4}^{+}{ }^{-}$ N. Karapınar (Karapınar 2009) reported that zeolite can be used as an adsorbent for the removal of ammonium and phosphorus from the wastewaters, and ammonium uptake of zeolite was about $0.4 \mathrm{mg} / \mathrm{g}$ for initial $\mathrm{NH}_{4}^{+}$concentration of $40 \mathrm{mg} / \mathrm{L}$ and zeolite dosage of $8 \mathrm{~g} / \mathrm{L}$. Demir and coworkers (Demir et al. 2002) studied the capacity of Bigadiç clinoptilolite for removing ions from synthetic aqueous solutions under varying conditions. The actual ion-exchange capacity of the conditioned fine and coarse clinoptilolite was found to be 0.57 and $0.38 \mathrm{mg} / \mathrm{g}$ zeolite, respectively. Another study was carried out on adsorption behavior of $\mathrm{NH}_{4}^{+}-\mathrm{N}$ from aqueous solution by activated carbons prepared from rice husk. The results obtained from this study 
indicated that the developed activated carbon had an adsorption capacity of $1.3 \mathrm{mg} / \mathrm{g}$ for $\mathrm{NH}_{4}^{+}-\mathrm{N}$ (Zhu et al. 2012).

Commercial activated carbon and zeolites are the most common adsorbents that have been implemented in the process of ammonium ion removal. These products are relatively effective for removal of pollutants but are expensive. In recent years, studies have been devoted to low-cost materials such as local mineral sorbents for the elimination of pollutants from water. These sorbents can be used in natural or modified forms. One such low-cost material is pumice. Pumice is an amorphous, porous volcanic rock which is composed mainly of $\mathrm{SiO}_{2}$ and whose porous structure is formed by dissolved gases precipitated during the cooling as the lava hurtles through the air (Gunduz et al. 1998, Lura et al. 2004). After Italy, Greece and China, Iran is the fourth largest pumice producer in the world (Bolen 2003). Due to its micro porous structure, pumice has a high specific surface area and low apparent density $\left(0.35-0.65 \mathrm{~g} / \mathrm{cm}^{3}\right)$ in aggregate form. Recently, many researchers used pumice for removal of cadmium (Panuccio et al. 2009), heavy metals (Moraci and Calabrò 2010), sulfur dioxide (Ozturk and Yildirim 2008) and disinfection by-products (Bekaroglu et al. 2010). However, based on our knowledge, it is seldom reported that the pumice stone is used in removal of $\mathrm{NH}_{4}^{+}$ion.

Response surface methodology (RSM) is an effective statistical technique and also a critical tool that is used for modeling and analyzing the effects of multiple parameters on the process (Baş and Boyac1 2007, Mansouri et al. 2012). The main advantages of this method are the reduced number of experimental trials, calculating the complex interaction between the independent variables, analysis and optimization as well as the improvement of existing design. In other words, this statistical approach is more practical compared to conventional experimental work as it arises from experimental methodology which includes interactive effects among the variables and, finally, it shows the overall effects of the variables on the process (Box and Draper 1987). Also, there are many classes of response surface designs that are occasionally useful in practice, such as Central Composite design, Box-Behnken design, Hybrid design and Three-level Factorial design (Khuri and Cornell 1996, Mason et al. 2003). So, due to the several advantages of pumice stone and its accessibility in Iran, the aim of the present work was to investigate its effectiveness for the removal of $\mathrm{NH}_{4}^{+}$ion from aqueous solution. The Central composite design (CCD) and RSM were used to design the experiments, build models and determine the optimum conditions.

\section{Materials and methods}

\section{Materials}

Natural pumice sample used in this study was obtained from the Kourdistan (Ghorve) of Iran and has a density of $0.64 \mathrm{~g}$ $\mathrm{cm}^{-3}$. Prior to use in the experiments, pumice samples were crushed and sieved through a $65 \times 65$ mesh sieve (based on Taylor standard seive) to obtained the particles size less than $\leq 0.227 \mathrm{~mm}$. $\mathrm{NH}_{4} \mathrm{Cl}$ supplied from Merck was used as adsorbate. $1000 \mathrm{ppm} \mathrm{NH}_{4} \mathrm{Cl}$ solution was prepared as a stock solution and then it was diluted to the required initial concentrations. Synthetic samples of aqueous solution were prepared by adding appropriate amounts of $\mathrm{NH}_{4} \mathrm{Cl}$ stock solution to deionized water to obtain ion concentrations of 20 , 40, 60, 80 and $100 \mathrm{mg} / \mathrm{l}$, respectively.

\section{Analysis and data calculation}

A Fourier transformed infrared (FTIR) was carried out using a spectrometer (WQF-510) in the transmittance mode with a resolution of $4 \mathrm{~cm}^{-1}$ in the range of $400-4000 \mathrm{~cm}^{-1}$ with $\mathrm{KBr}$ pellets technique. FTIR is an instrument that indicates the main functional groups of adsorbent and these groups play the main role in adsorbate removal from solutions. So that, any wave in the range of $400-4000 \mathrm{~cm}^{-1}$ indicates the particular functional group (Bardakçi and Bahçeli 2010).

The chemical characteristics of the pumice samples were determined by a XRD (Shimadzu XRD-6000). The $\mathrm{NH}^{+}$ion concentration in the aqueous phase was determined using the standard Nesslerre agent method employing a Perkin-Elmer 402 UV spectrophotometer. A surface morphology of pumice granular was studied by scanning electron microscopy using a Philips XL30 microscope at an accelerating voltage of $10 \mathrm{kV}$. After oven-drying of the pumice granular for 12 hours, the sample was coated with a platinum layer using an SCDOOS sputter coater (BAL-TEC, Sweden) in an argon atmosphere. Subsequently, the sample was scanned and photomicrographs were obtained.

\section{Adsorption experiment}

Adsorption experiments were carried out in $500 \mathrm{~mL}$ Erlenmeyer flasks by using five different concentrations of $\mathrm{NH}_{4}+$, mixing rate at temperature of $23 \pm 2^{\circ} \mathrm{C}$ and $\mathrm{pH}=7$. A certain amount of pumice granular was mixed with $250 \mathrm{~mL}$ ammonium solutions of concentrations ranging from 20 to $100 \mathrm{mg} / \mathrm{L}$. The amount of $\mathrm{NH}_{4}^{+}$adsorbed on the pumice granular was calculated from the difference between the initial concentration of $\mathrm{NH}_{4}^{+}$and the residual $\mathrm{NH}_{4}^{+}$concentration in the solution. The calculation can be described by the following equation (Wang et al. 2011):

$$
q_{e}=\frac{\left(C_{0}-C_{e}\right) V}{M}
$$

where $q_{\mathrm{e}}(\mathrm{mg} / \mathrm{g})$ is the adsorbent capacity, $C_{0}(\mathrm{mg} / \mathrm{L})$ is the initial concentration of $\mathrm{NH}_{4}^{+}, C_{\mathrm{e}}(\mathrm{mg} / \mathrm{L})$ is the final or equilibrium concentration of $\mathrm{NH}_{4}^{+}, \mathrm{V}$ is the experimental solution volume $(\mathrm{L})$, and $\mathrm{M}$ is the weight of pumice granular $(\mathrm{g})$.

\section{Experimental design}

RSM along with the Design of Experiments remove systematic errors with an estimate of the experimental error and also reduce the number of experiments to obtain the optimum operating conditions. There are many classes of response surface designs that are occasionally useful in practice such as Central Composite design, Box-Behnken design, Hybrid design and Three-level Factorial design (Khuri and Cornell 1996, Mason et al. 2003). Among these methods the CCD is the most frequently used one under RSM. The RSM employed in the current study was a $\mathrm{CCD}$ involving four different factors; pumice dosage (A), $\mathrm{NH}^{+}$concentration (B), mixing rate $(\mathrm{C})$ and contact time (D). The range investigated for these variables is presented in Table 1 . The $\mathrm{NH}_{4}^{+}$removal efficiency and adsorption capacity of pumice granular were evaluated based on the CCD experimental plan (Table 2). The design consisted of $2^{\mathrm{k}}$ factorial points augmented by $2 \mathrm{k}$ axial points and a center point where $\mathrm{k}$ is the number of variables. The 
coded values of four operating variables $(A, B, C$ and $D)$ were set at five levels: -1.5 (minimum), $-1,0$ (central), +1 , and +1.5 (maximum). These five levels were assessed based on the full face-centered CCD experimental plan.

Accordingly, 30 experiments $\left(=2^{\mathrm{k}}+2 \mathrm{k}+6\right)$, where $\mathrm{k}$ is the number of factors, were conducted with 25 experiments organized in a factorial design (including 16 factorial points, 8 axial points and 1 center point) and the remaining 5 involving the replication of the central point to get a good estimate of the experimental error. Repetition experiments were carried out followed by order of runs designed by Design of Experiments (DOE) as shown in Table 2.

Table 1. Experimental range and levels of the independent variables

\begin{tabular}{cccccc}
\hline Variables & \multicolumn{4}{c}{ Range and levels } \\
\cline { 2 - 6 } & $-\alpha(-1.5)$ & -1 & 0 & 1 & $+\alpha(1.5)$ \\
\hline Pumice dosage, $\mathrm{g} / \mathrm{L}$ & 20 & 40 & 60 & 80 & 100 \\
\hline Initial ammonium concentration, $\mathrm{mg} / \mathrm{L}$ & 20 & 40 & 150 & 200 & 250 \\
\hline Mixing rate & 100 & 90 & 120 & 150 \\
\hline Contact time (min) & 60 & 900 & 180 \\
\hline
\end{tabular}

Table 2. Experimental conditions and results of central composite design

\begin{tabular}{|c|c|c|c|c|}
\hline \multirow{3}{*}{ Run } & \multicolumn{4}{|c|}{ Variables } \\
\hline & Factor 1 & Factor 2 & Factor 3 & Factor 4 \\
\hline & $\begin{array}{l}\text { A: Pumice } \\
\text { dosage }\end{array}$ & $\begin{array}{c}\text { B: Initial } \\
\mathrm{NH}_{4}+\text { Conc. }\end{array}$ & $\begin{array}{l}\text { C: Mixing } \\
\text { speed }\end{array}$ & $\begin{array}{c}\text { D: Contact } \\
\text { time }\end{array}$ \\
\hline & $g / l$ & $\mathrm{mg} / \mathrm{l}$ & $\mathrm{rpm}$ & $\min$ \\
\hline 1 & 60 & 60 & 200 & 120 \\
\hline 2 & 60 & 60 & 200 & 120 \\
\hline 3 & 20 & 100 & 300 & 180 \\
\hline 4 & 60 & 60 & 200 & 120 \\
\hline 5 & 100 & 100 & 100 & 60 \\
\hline 6 & 100 & 20 & 300 & 60 \\
\hline 7 & 60 & 60 & 200 & 120 \\
\hline 8 & 60 & 60 & 200 & 150 \\
\hline 9 & 20 & 100 & 300 & 60 \\
\hline 10 & 100 & 100 & 300 & 60 \\
\hline 11 & 20 & 20 & 300 & 60 \\
\hline 12 & 100 & 20 & 100 & 180 \\
\hline 13 & 100 & 100 & 300 & 180 \\
\hline 14 & 60 & 60 & 200 & 120 \\
\hline 15 & 20 & 20 & 100 & 180 \\
\hline 16 & 20 & 20 & 100 & 60 \\
\hline 17 & 80 & 60 & 200 & 120 \\
\hline 18 & 100 & 100 & 100 & 180 \\
\hline 19 & 60 & 60 & 250 & 120 \\
\hline 20 & 100 & 20 & 100 & 60 \\
\hline 21 & 40 & 60 & 200 & 120 \\
\hline 22 & 100 & 20 & 300 & 180 \\
\hline 23 & 60 & 60 & 200 & 90 \\
\hline 24 & 20 & 20 & 300 & 180 \\
\hline 25 & 60 & 60 & 200 & 120 \\
\hline 26 & 20 & 100 & 100 & 180 \\
\hline 27 & 60 & 40 & 200 & 120 \\
\hline 28 & 60 & 80 & 200 & 120 \\
\hline 29 & 60 & 60 & 150 & 120 \\
\hline 30 & 20 & 100 & 100 & 60 \\
\hline
\end{tabular}

\begin{tabular}{|c|c|c|c|}
\hline \multicolumn{4}{|c|}{ Responses } \\
\hline \multicolumn{2}{|c|}{$\begin{array}{l}\text { Ammonium ion } \\
\text { removal, } \%\end{array}$} & \multicolumn{2}{|c|}{$\mathrm{q}_{\mathrm{e}}(180 \mathrm{~min}), \mathrm{mg} / \mathrm{g}$} \\
\hline Actual & predicted & Actual & predicted \\
\hline$\%$ & $\%$ & $\mathrm{mg} / \mathrm{g}$ & $\mathrm{mg} / \mathrm{g}$ \\
\hline 45.3 & 40.64 & 0.140 & 0.13 \\
\hline 40.2 & 40.64 & 0.125 & 0.13 \\
\hline 24.12 & 26.33 & 0.330 & 0.28 \\
\hline 37.6 & 40.64 & 0.115 & 0.13 \\
\hline 32.77 & 33.38 & 0.090 & 0.091 \\
\hline 66.25 & 64.69 & 0.050 & 0.046 \\
\hline 43.1 & 40.64 & 0.120 & 0.13 \\
\hline 47.69 & 42.05 & 0.133 & 0.13 \\
\hline 20.7 & 20.70 & 0.273 & 0.28 \\
\hline 37.88 & 39.33 & 0.110 & 0.11 \\
\hline 37.79 & 38.48 & 0.117 & 0.11 \\
\hline 61.3 & 64.37 & 0.040 & 0.026 \\
\hline 44.5 & 44.97 & 0.114 & 0.11 \\
\hline 43.6 & 40.64 & 0.117 & 0.13 \\
\hline 39.5 & 38.16 & 0.100 & 0.089 \\
\hline 32.64 & 32.52 & 0.105 & 0.089 \\
\hline 51.2 & 46.24 & 0.114 & 0.097 \\
\hline 39.5 & 39.01 & 0.113 & 0.091 \\
\hline 46.3 & 42.13 & 0.140 & 0.13 \\
\hline 57.18 & 58.73 & 0.037 & 0.026 \\
\hline 29.88 & 35.03 & 0.120 & 0.16 \\
\hline 71.4 & 70.32 & 0.040 & 0.046 \\
\hline 35.13 & 39.23 & 0.102 & 0.13 \\
\hline 43.9 & 44.12 & 0.110 & 0.11 \\
\hline 39.4 & 40.64 & 0.106 & 0.13 \\
\hline 19.5 & 20.37 & 0.270 & 0.26 \\
\hline 41.67 & 46.03 & 0.080 & 0.097 \\
\hline 31.16 & 35.25 & 0.128 & 0.13 \\
\hline 39.7 & 39.15 & 0.108 & 0.12 \\
\hline 18.3 & 14.74 & 0.246 & 0.26 \\
\hline
\end{tabular}




\section{Mathematical modeling}

After conducting the experiments, the relationship between the dependent and independent variables was calculated using the following equation (Box and Draper 1987):

$$
Y=\beta_{0}+\beta_{i} X_{i}+\beta_{j} X_{j}+\beta_{i i} X_{i}^{2}+\beta_{j j} X_{j}^{2}+\beta_{i j} X_{i} X_{j}+\ldots
$$

Where $\mathrm{Y}, \mathrm{i}, \mathrm{j}, \mathrm{B}, \mathrm{X}$ represent process response, linear coefficient, quadratic coefficient, regression coefficient and coded independent variables respectively. Model terms are accepted or rejected based on the probability of error $(\mathrm{P})$ value with $95 \%$ confidence level. The results obtained from CCD were entirely examined by means of analysis of variance (ANOVA) by Design Expert software. Three-dimensional (3D) plots and their respective contour plots were obtained due to the effect of the two factors while other factors can be changed by default. Therefore, the results of CCD can be presented in 3D presentations with contours. This will help to study the simultaneous interaction of the variables on the responses.

\section{Results and discussion}

\section{Pumice characterization}

The chemical analysis of pumice granular samples was determined using XRD. The results showed the composition as $\mathrm{SiO}_{2}(67 \%), \mathrm{Al}_{2} \mathrm{O}_{3}(15.6 \%), \mathrm{K}_{2} \mathrm{O}(5.4 \%), \mathrm{Fe}_{2} \mathrm{O}_{3}(1.1 \%), \mathrm{Na}_{2} \mathrm{O}$ (3.7\%), $\mathrm{CaO}(3.9 \%), \mathrm{MgO}(0.2 \%)$ and etc. As seen from the values, the two most important components of the sample are $\mathrm{SiO}_{2}$ and $\mathrm{Al}_{2} \mathrm{O}_{3}$

FTIR spectrum is the feature of a particular compound that gives the information about its functional groups, molecular geometry and inter/intra molecular interactions. Fig. 1 shows the FTIR spectra of pumice granular. The peaks at 467 and $798 \mathrm{~cm}^{-1}$ in the FTIR spectrum of the pumice (Fig. 1) may have resulted from the $\mathrm{Si}-\mathrm{O}$ bending strength vibrations of the $\mathrm{SiO}_{2}$ which constituted the structure. The strong peak around $1070 \mathrm{~cm}^{-1}$ may have resulted from $\mathrm{Si}-\mathrm{O}$ stretching vibrations (Ersoy et al. 2010). The other important peak was detected around $3406 \mathrm{~cm}^{-1}$. This peak pointed out the $\mathrm{OH}$ stretching vibrations of the water (moisture) which was adsorbed by the sample from the outside environment (Grim 1968). The water adsorbed from the outside environment also produces a deformation vibration peak around $1620 \mathrm{~cm}^{-1}$ (Ersoy et al. 2010).

SEM images detailing the micro-structure (i.e., inner pore structure) of the pumice are displayed in Fig. 2. According to SEM images, the pumice sample has irregular or oval shaped and fibrous cavities (or pores), in addition, it may be said that these pores are either in closed or in open forms. The pore diameter of these cavities varied between $1 \mu \mathrm{m}$ and $30 \mu \mathrm{m}$ and these cavities generally did not intersect each other. It is reported that the connectivity of the pore structure of pumice may range from completely closed to completely open (Lura et al. 2004). Moreover, the glassy phase structure of the pumice can be seen in Fig. 2. According to the element analysis of the $\mathrm{XRD}$, the biggest peaks were recorded as related to Si and Al.

\section{Model fitting and statistical analysis}

The design matrix in the term of coded factors and experimental results of the $\mathrm{NH}_{4}^{+}$removal and equilibrium adsorption capacity are presented in Table 2 . The obtained results were then, subjected to RSM to evaluate the relationship between the pumice dosage (A), $\mathrm{NH}_{4}^{+}$concentration (B), mixing rate (C) and contact time (D). The predicted values obtained from model fitting technique using the design expert software for both responses were seen to be sufficiently correlated to the observed values (Table 2). The predicted response values slightly deviated from the experimental data. Multiple regression coefficients of a second-order polynomial models describing the $\mathrm{NH}_{4}^{+}$ removal and equilibrium adsorption capacity are summarized in Table 2. For determination of coefficients' significance and the suitability of proposed models, the ANOVA technique was performed. The significance or insignificant of each coefficient was determined by P-value. The P-values lower than 0.05 indicated that coefficient of a model term is significant. The resulting ANOVA are listed in Table 3 for each of the model terms. Based on the P-values, the first order effects of all variables (A, B, D and $C$ ) and two level interaction of $A$ and $B$ (AB) are significant for both process responses. Other model terms are not significant (with probability values larger than

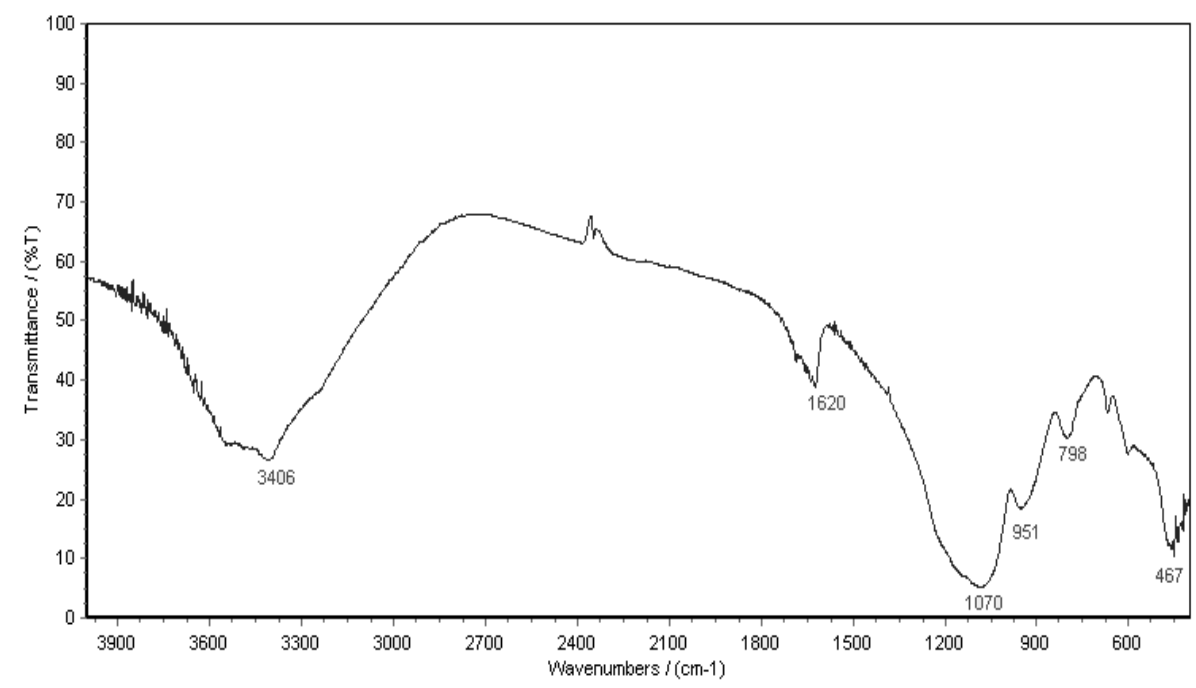

Instrument model=WQF-510 resolution=4 scan times $=10$

Fig. 1. FTIR spectrum of the pumice 


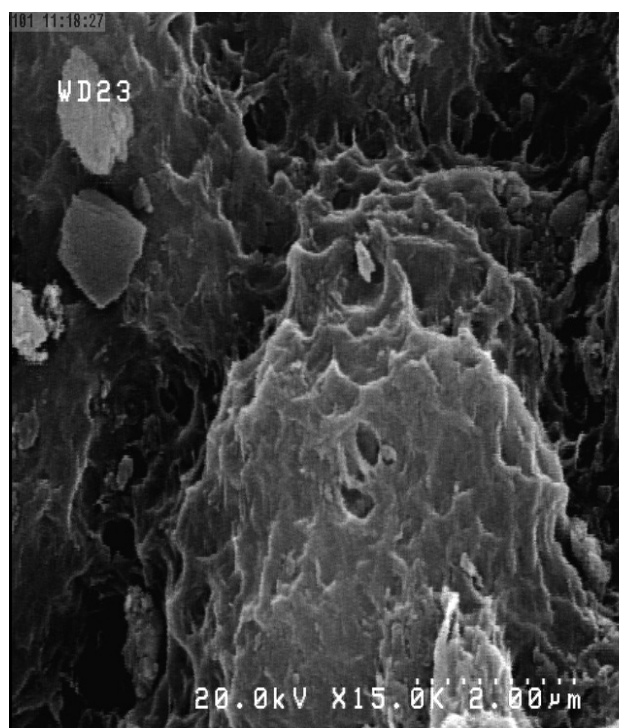

(a)

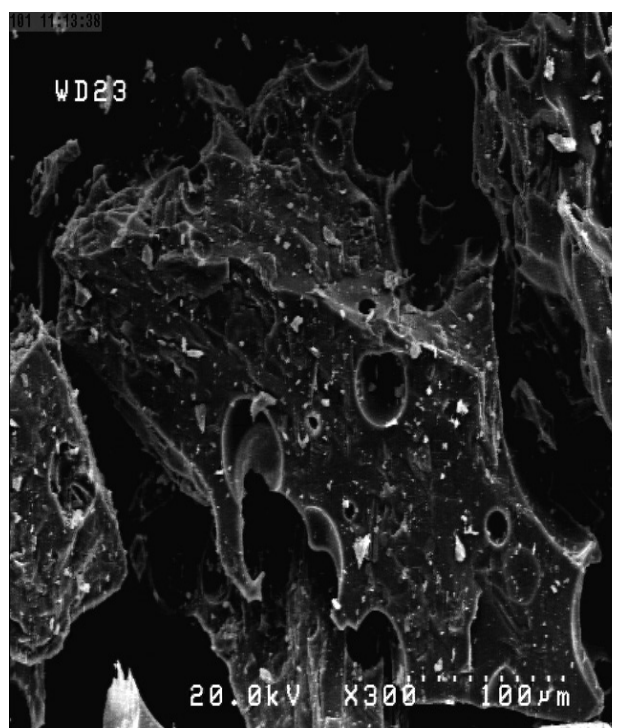

(b)

Fig. 2. SEM images of the pumice sample (a) scaled up by $\times 15$ times, (b) scaled up by $\times 300$ times

0.05). In order to simplify the model, these insignificant model terms $\left(\mathrm{A}^{2}, \mathrm{~B}^{2}, \mathrm{C}^{2}, \mathrm{D}^{2}, \mathrm{AC}, \mathrm{AD}, \mathrm{BC}\right.$ and $\left.\mathrm{BD}\right)$ were eliminated.

The analysis of variance (ANOVA) was employed to examine the significance of the obtained models under an extensive range of operating conditions. The results are depicted in Table 4 (numerically) and Figs. 3-5 (graphically). The ANOVA results revealed that the quadratic model was significant at the $5 \%$ confidence level respectively for $\mathrm{NH}_{4}^{+}$ removal and equilibrium adsorption capacity since $P$ values were less than 0.05 for both models. Fisher F-test value explains the distribution of the actual data around the fitted model. According to the calculated F-test values (86.66 for $\mathrm{NH}_{4}+$ removal and 92.38 for equilibrium adsorption capacity) along with a very low probability value for both responses ( $\mathrm{p}$ model $<0.0001$ ), it can be concluded that both models are highly significant.

The fitting of models to the empirical data was tested by calculating determination coefficient $\left(R^{2}\right)$. The high values of $R^{2}$ (0.95 for $\mathrm{NH}_{4}^{+}$removal and 0.94 for equilibrium adsorption capacity) designate the capability of developed models to satisfactorily describe the system behavior within the investigated range of operating parameters.

Adequate Precision (AP) compares the range of the predicted values at the design points to the average prediction error. Ratios greater than 4 indicate adequate model discrimination and can be used to navigate the design space defined by the CCD (Mason et al. 2003). In this study, the ratios of AP value were found to be 39.32 and 33.6 for $\mathrm{NH}_{4}^{+}$removal and equilibrium adsorption capacity respectively, which are greater than 4 and considered satisfied results.

Other important information about fitting, reliability, adequacy, the correlation between the observed and predicted data, and homogeneous and heterogeneous error variances of the models performance can be attained in the diagnostic plots (Figs. 3-5). These figures give an obvious sight about any deficiency of the models fitting to the experimental data Figs. $3 \mathrm{a}$ and $3 \mathrm{~b}$ display the normal probability of the residuals for both responses, to confirm whether the standard deviations between the actual and the predicted response values follow a normal distribution (Lee and Gilmore 2005). Points and points' clusters in Figs. 3a and $3 \mathrm{~b}$ indicate that experimental values are distributed relatively near to the straight line and show satisfactory correlation between these values. Therefore, there are no serious violations in the hypothesis that errors are normally distributed and independent of each other, and also that the error variances are homogeneous and residuals are independent (Kusic et al. 2011). The prediction of Amunium ion removal efficincy and $\mathrm{q}_{\mathrm{e}}$ (Eqs. 2 and 3) was compared with the experimental values given in Tab. 2 and shown in Fig. 4. It can be seen from Fig4 that in the both models equations predictions are statistically a satisfactory match with the experimental values. Therefore, this model can be used to navigate the design space. In fact, the figures $4 \mathrm{a}$ and $4 \mathrm{~b}$ depict the relationship between the values of $\mathrm{R}^{2}$ and adjusted $\mathrm{R}^{2}$. The $\mathrm{R}^{2}$ values of 0.95 and 0.94 are in reasonable agreement with the Adj $\mathrm{R}^{2}$ values of 0.93 and 0.91 for the $\mathrm{NH}_{4}^{+}$removal and equilibrium adsorption capacity, which shows a very good agreement between the predicted and actual data.

The plots of residual against predicted responses (Figs. $5 \mathrm{a}$ and $5 \mathrm{~b}$ ) check the assumption of constant variance. It can be seen that all points of experimental runs are randomly distributed and all values lie within the range of -3 and 3 . These findings indicate that the models proposed by RSM are satisfactory and that the constant variance assumptions were confirmed.

\section{Interactive effect of the variables on the $\mathrm{NH}^{+}$ removal efficiency}

RSM is applied to build up mathematical relationships between the process variables and the responses of interest, using the simulation results. RSM is one of the best known empirical modeling techniques, which helps in carrying out the analysis of experiments with the least experimental effort. From the ANOVA indicated in Table 4, the main order effects of all variables (A, B, C and D) and the two level interaction between pumice dosage and initial concentration of $\mathrm{NH}_{4}^{+}(\mathrm{AB})$ are the significant model terms on the both process responses. ANOVA results also indicate that the effects of $\mathrm{A}$ and $\mathrm{B}$ do not depend 


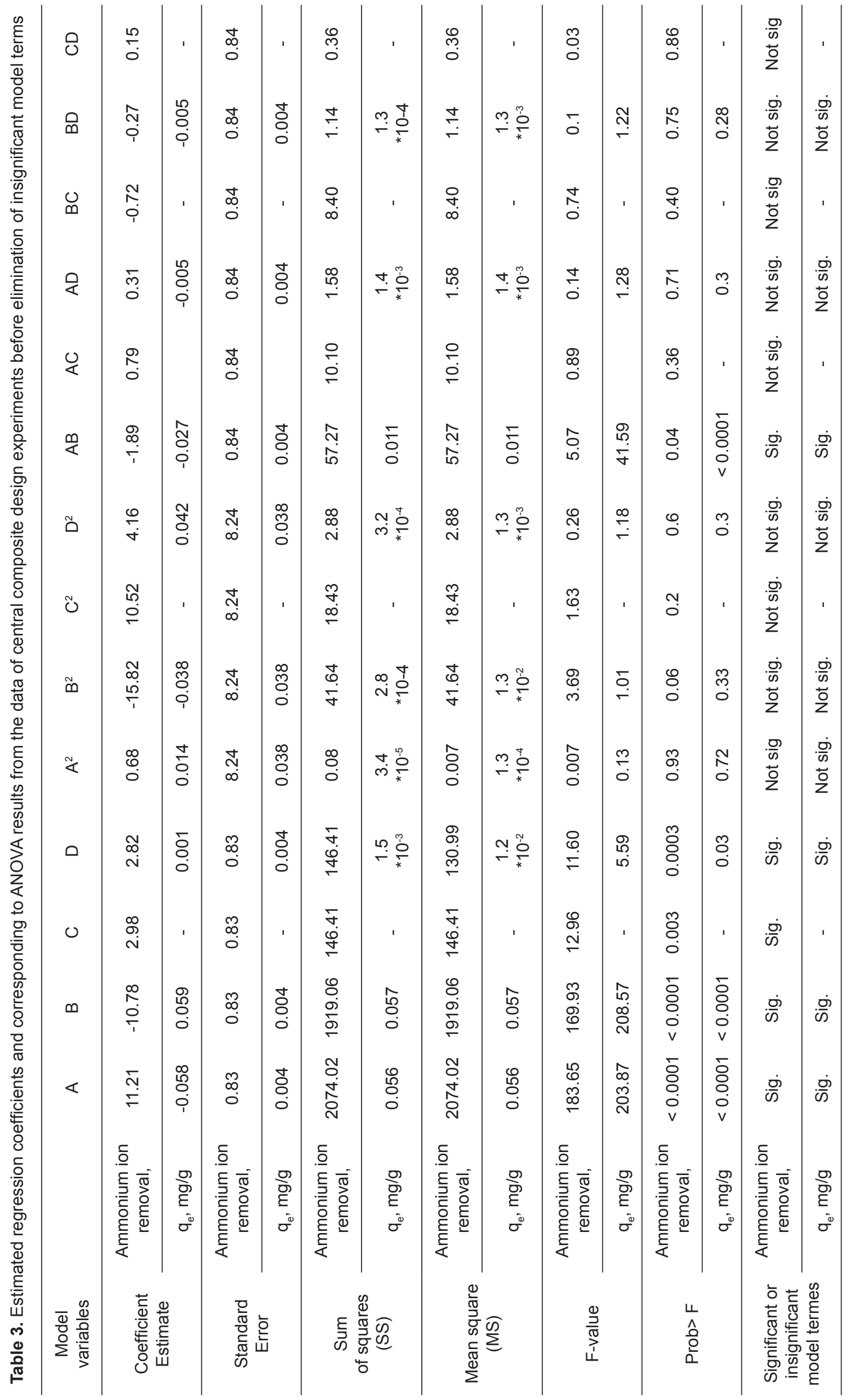


Table 4. Analysis of variance (ANOVA) for fit of Ammonium ion removal $(\%)$ and $\mathrm{q}_{\mathrm{e}}(\mathrm{mg} / \mathrm{g})$ from central composite design after elimination of insignificant model terms

\begin{tabular}{|c|c|c|c|c|c|c|c|c|c|c|c|c|}
\hline Model & $\begin{array}{c}\text { Type } \\
\text { of model }\end{array}$ & $\begin{array}{c}\text { Significant } \\
\text { model terms }\end{array}$ & $\mathrm{F}$ value & Prob > F & SD & $R^{2}$ & Adj. $R^{2}$ & Pred. $R^{2}$ & Mean & $\begin{array}{c}\text { Adeq. } \\
\text { precision }\end{array}$ & PRESS & $\begin{array}{c}\text { Probability for } \\
\text { lack of fit }\end{array}$ \\
\hline $\begin{array}{c}\text { Ammonium } \\
\text { ion removal, } \\
\%\end{array}$ & $\begin{array}{l}\text { Quadratic } \\
\text { model }\end{array}$ & $A, B, C, D, A B$ & 86.66 & $<0.0001$ & 3.16 & 0.95 & 0.94 & 0.93 & 40.64 & 39.3 & 309.15 & 0.4520 \\
\hline $\mathrm{qe}, \mathrm{mg} / \mathrm{g}$ & $\begin{array}{l}\text { Quadratic } \\
\text { model }\end{array}$ & $A, B, C, A B$ & 92.38 & $<0.0001$ & 0.018 & 0.94 & 0.93 & 0.91 & 0.13 & 33.6 & 0.013 & 0.08 \\
\hline
\end{tabular}

$\mathrm{R}^{2}$ : determination coefficient, Adj. $\mathrm{R}^{2}$ : adjusted $\mathrm{R}^{2}$, Adeq. precision: adequate precision, SD: standard deviation, PRESS: predicted residual error sum of squares

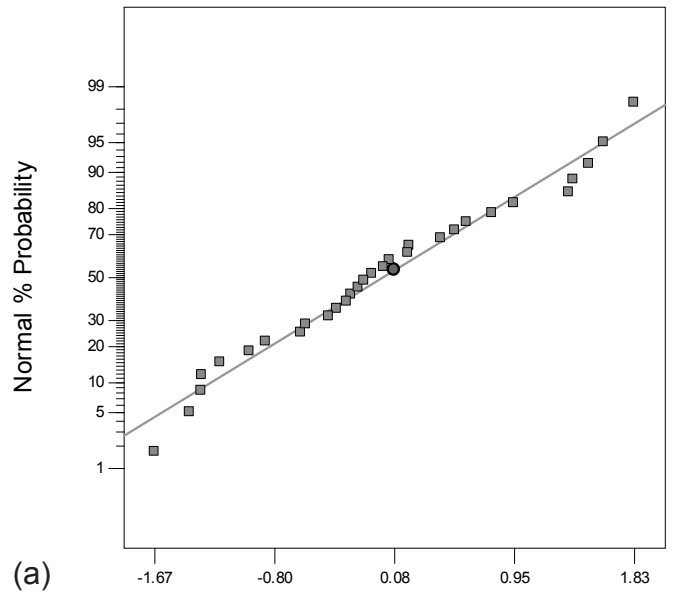

Studentized Residuals

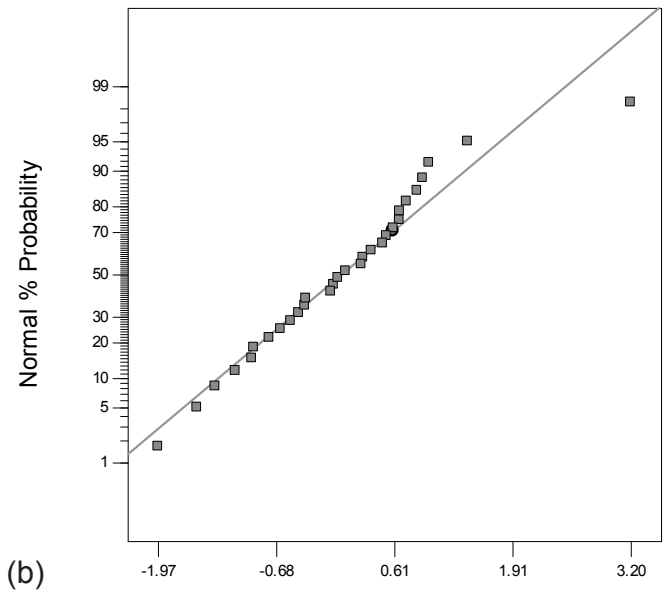

Studentized Residuals

Fig. 3. Normal probability plots of residual for (a) $\mathrm{NH}_{4}{ }^{+}$removal (\%), (b)qe (mg/g)
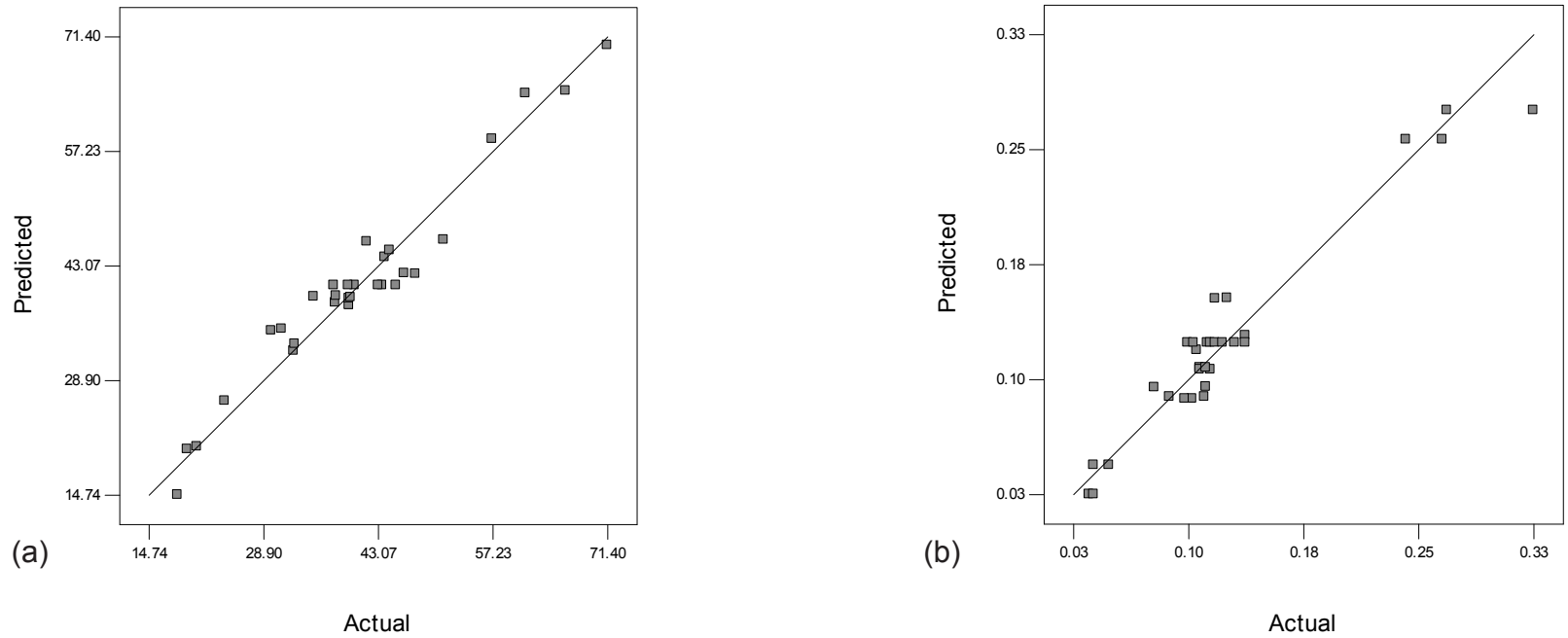

Fig. 4. Predicted vs. actual values plots for(a) $\mathrm{NH}_{4}{ }^{+}$removal (\%), (b) qe (mg/g)

on the level of factors $\mathrm{C}$ and $\mathrm{D}$, whereas factors $\mathrm{A}$ and $\mathrm{B}$ do affect each other. Hence $\mathrm{A}$ and $\mathrm{B}$ are said to be interacting. The following regression equation is the reduced quadratic models in terms of implied factors for the both responses: Based on the results obtained from ANVA (Table 4), the response surface models constructed in this study for predicting $\mathrm{NH}_{4}^{+}-\mathrm{N}$ removal efficiency and equilibrium adsorption capacity were considered reasonable. The final regression models, in terms of their coded factors as determined by the Design Experts software for both responses, are expressed by the following equations.

Amonium ion removal efficincy $(\%)=$ $=+40.64+11.21 \mathrm{~A}-10.78 \mathrm{~B}+2.98 \mathrm{C}+2.82 \mathrm{D}-1.89 \mathrm{AB}$ 
(a)

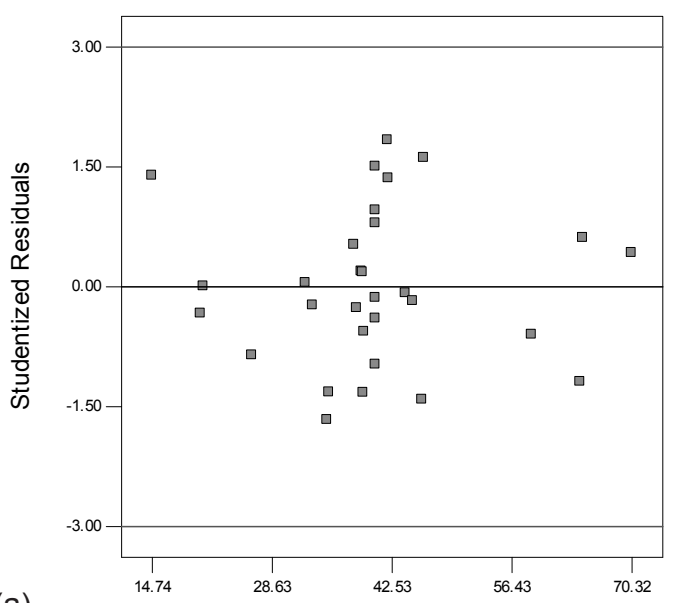

Predicted

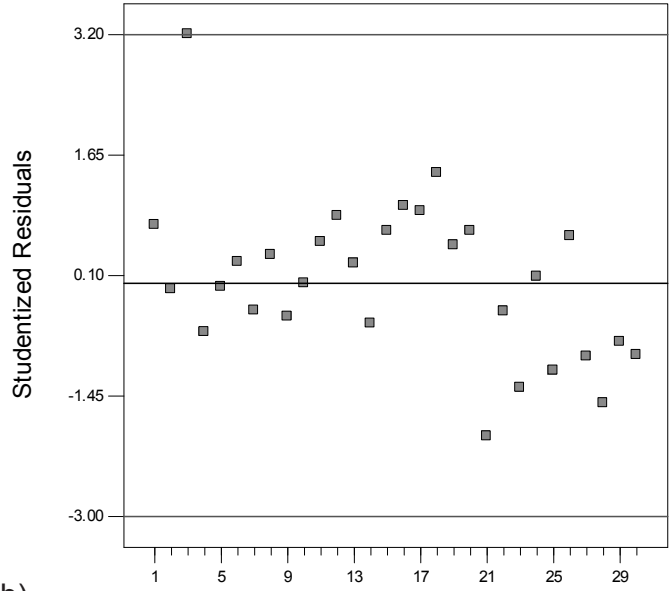

(b)

Run Number

Fig. 5. Plots of residual versus predicted responses for (a) $\mathrm{NH}_{4}{ }^{+}$removal (\%) and (b) qe (mg/g)

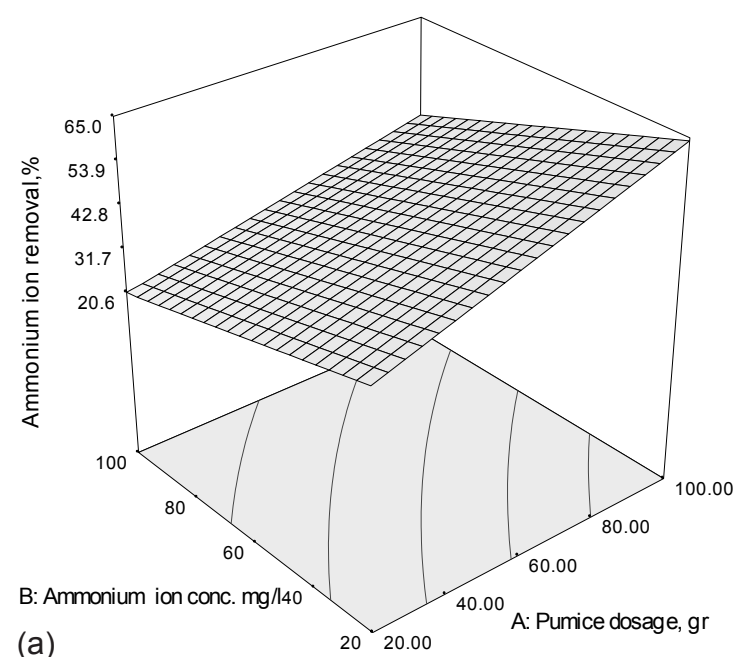

(a)

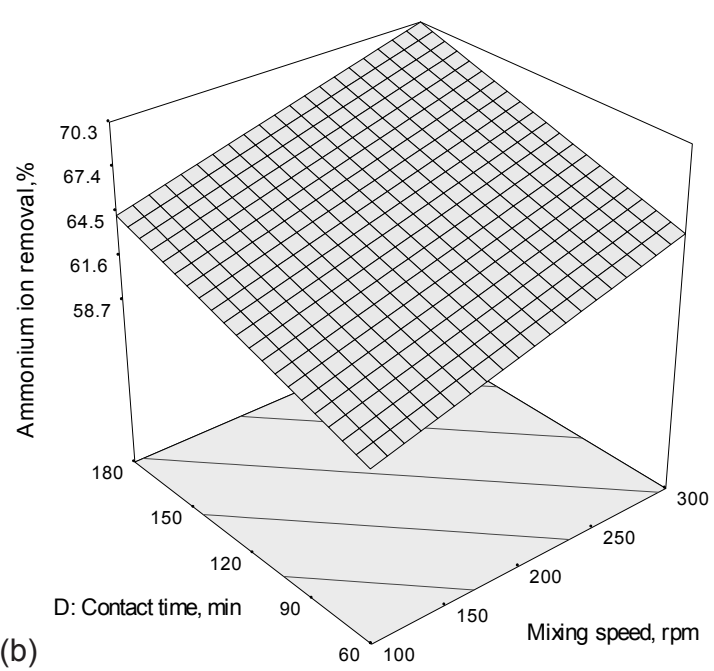

Fig. 6. Response surface plots for $\mathrm{NH}_{4}{ }^{+}$removal (\%) with respect to: (a). pumice dosage and ammonium ion concentration, (b) mixing speed (rpm) and contact time $(\mathrm{min})$

$\mathrm{qe}, \mathrm{mg} / \mathrm{l}=+0.13-0.058 \mathrm{~A}+0.059 \mathrm{~B}+0.1 \mathrm{C}-0.027 \mathrm{AB}$

The relationship between the responses and variables was visualized by the three-dimensional surface plots to see the influence of the parameters. Fig. 6a shows threedimensional contour plots of the model for variation in $\mathrm{NH}_{4}^{+}$ removal, as a function of pumice dosage (A) and initial $\mathrm{NH}_{4}{ }^{+}$concentration at constant values of mixing rate (200 $\mathrm{rpm})$ and contact time (60 $\mathrm{min})$. It is clear from this figure that one of the most significant variables on the response was pumice dosage. The adsorption of $\mathrm{NH}_{4}^{+}$increased with increase in pumice dosage, presumably from the greater availability of active binding sites and to the presence of a greater surface area for adsorption. But the amount of $\mathrm{NH}_{4}^{+}$ions adsorbed per unit mass of adsorbent decreased with increase in adsorbent dose (Fig 6a). The phenomenon that the reduction of the adsorption unit of $\mathrm{NH}_{4}-\mathrm{N}$ on the pumice granular was mainly due to the fact that the total adsorption sites increased with the increase of the dosage of pumice granular, but the total amount of $\mathrm{NH}_{4}-\mathrm{N}$ in the solution still remained the same.

As shown in Fig. 6a, an increase in the initial ammonium concentration from 20 to $100 \mathrm{mg} / \mathrm{L}$ caused an increase in the response. Increasing the initial $\mathrm{NH}_{4}^{+}$ions concentration would increase the mass transfer driving force and therefore the rate at which $\mathrm{NH}_{4}^{+}$ions pass from the solution to the particle surface.

Figure $6 \mathrm{~b}$ shows the three-dimensional plot of the model for $\mathrm{NH}_{4}^{+}$removal with respect to mixing rate and contact time the design space, with pumice dosage at its high level $(100 \mathrm{~g} / \mathrm{L})$ and initial ammonium concentration at its low level (20 mg/l). As shown in this figure, the contact time (range 60-120 $\mathrm{min}$ ) did not show any strong effect on the process, as only a small difference is observed in the results obtained with different contact time. However, the improvement of $\mathrm{NH}_{4}^{+}$ removal efficiency (about $6 \%$ ) was observed with increase of contact time from 60 to $120 \mathrm{~min}$. Therefore, contact time of 60 min was chosen as optimal parameter in the work. These 
results also show that $\mathrm{NH}^{+}$adsorption by pumice granular was very fast at the initial period of contact time and then to become slow with the increase of contact time. This was caused by strong attractive forces between the $\mathrm{NH}_{4}^{+}$ions and the sorbent; fast diffusion onto the external surface was followed by a fast pore diffusion into the intra particle matrix to attain rapid equilibrium. As shown in Fig. 6b, an increase in the mixing rate increases the $\mathrm{NH}_{4}^{+}$removal. It can be stated that increase the mixing rate cause increases the contact between adsorbent and adsorbate, this event improved the access of $\mathrm{NH}_{4}^{+}$ions to the active binding sites of pumice granular as a result the NH4 increases. Perturbation plot (Fig. 7) also shows the comparative effects of the variables on $\mathrm{NH}_{4}^{+}$removal efficiency. In Fig. 7, steep lines in pumice dosage and ammonium concentration show that the response of $\mathrm{NH}_{4}^{+}$removal efficiency was very sensitive to these factors. The maximum modeled $\mathrm{NH}_{4}^{+}$removal was $70 \%$ at pumice dosage, initial $\mathrm{NH}_{4}{ }^{+}$concentration and mixing rate of $100 \mathrm{~g} / \mathrm{l}$, $20 \mathrm{mg} / \mathrm{l}$ and $300 \mathrm{rpm}$, respectively. Meanwhile, the minimum predicted response $(20.6 \%)$ was obtained at pumice dosage, initial $\mathrm{NH}_{4}^{+}$concentration and mixing rate of $20 \mathrm{~g} / 1,100 \mathrm{mg} / \mathrm{l}$ and $100 \mathrm{rpm}$, respectively.

Fig. 8 shows response surface and contour plots of the model for variation in $\mathrm{q}_{\mathrm{e}}$, as a function of pumice dosage (A) and initial ammonium concentration (B) with three different mixing rates $(100,200$ and 300). As can be seen in the figures $(8 \mathrm{a}-\mathrm{c})$, the same trends were found as the mixing rate changed from 100 to 300 . In Fig. 8, the response increased upon increasing the $\mathrm{NH}_{4}^{+}$concentration and decreasing the pumice dosage. It is demonstrated by perturbation plot (Fig. 9). The highest $q_{e}$ was attained when ammonium ion concentration and mixing rate were high, while the pumice dosage was low as can be seen from Fig. 8. It must be noted that qe values were calculated based on contact time of $180 \mathrm{~min}$. It was observed that the equilibrium adsorption capacity decreased with increasing the amount of pumice dosage from 20 to $100 \mathrm{~g} / \mathrm{L}$. The optimum for the maximum equilibrium adsorption capacity was found to be $0.28 \mathrm{mg} / \mathrm{g}$. According to obtained results, increases the adsorbent dosage can be attributed to increase the pumice surface area and the

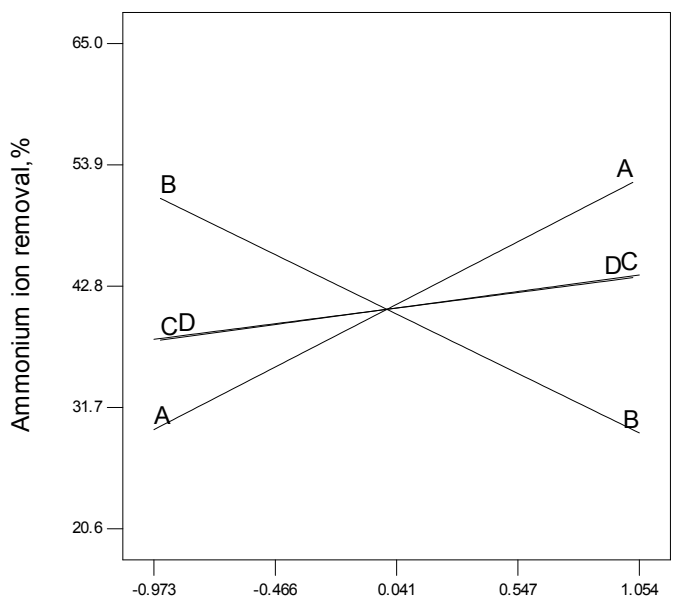

Deviation from Ref erence Point

Fig. 7. Perturbation plot for $\mathrm{NH}_{4}^{+}$removal availability of more adsorption sites, nevertheless, the values of equilibrium adsorption capacity decreased with an increase in the adsorbent dosage. The primary factor explaining this characteristic is that adsorption sites remain unsaturated

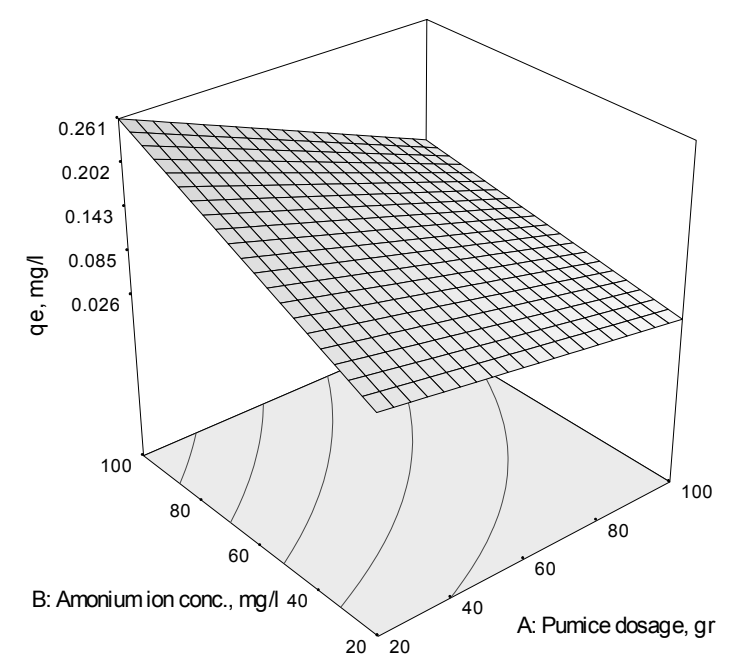

(a)

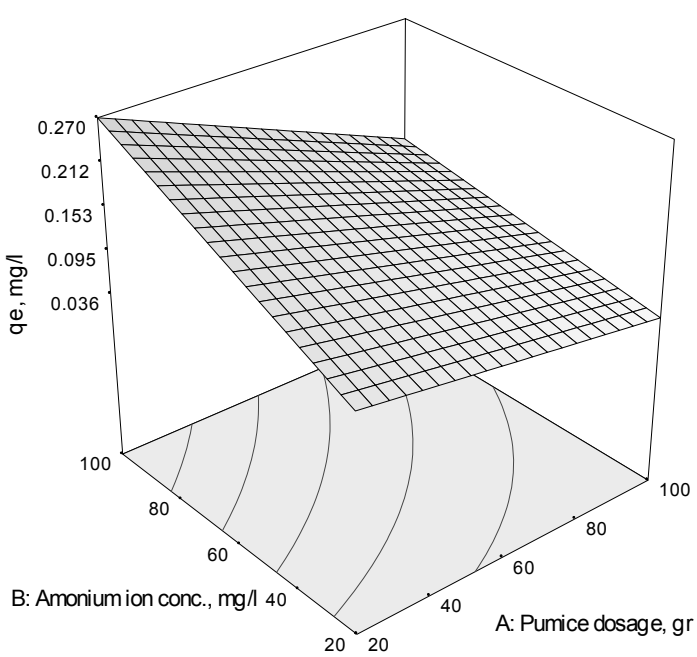

(b)

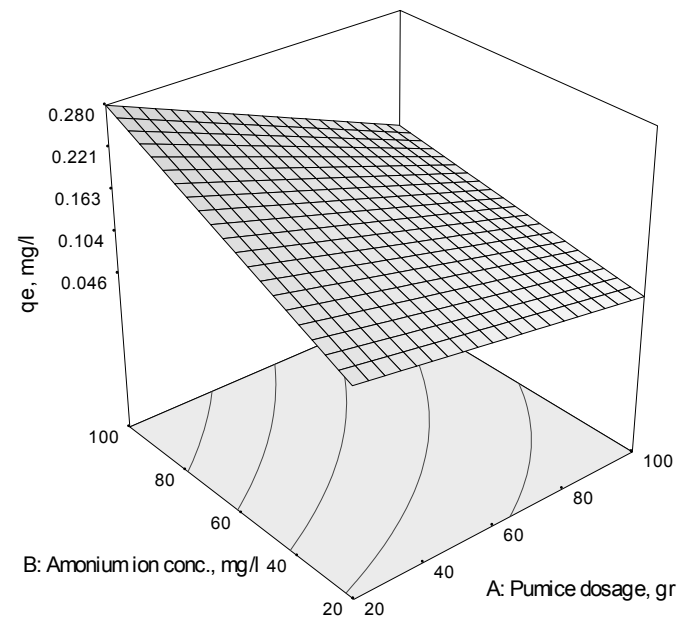

(c)

Fig. 8. Response surface plots for $\mathrm{q}_{\mathrm{e}}(\mathrm{mg} / \mathrm{g})$ with respect topumice dosage and ammonium ion concentration at constant value of mixing rate of (a) 100, (b) 200 and (c) $300 \mathrm{rpm}$ 
during the adsorption reaction whereas the number of sites available for adsorption increased by increasing the adsorbent dosage. This means that the higher ratio of the ammonium ion concentration to the surface binding site on the sorbent could be obtained at lower pumice dosage and higher initial $\mathrm{NH}_{4}^{+}$ ion concentration.

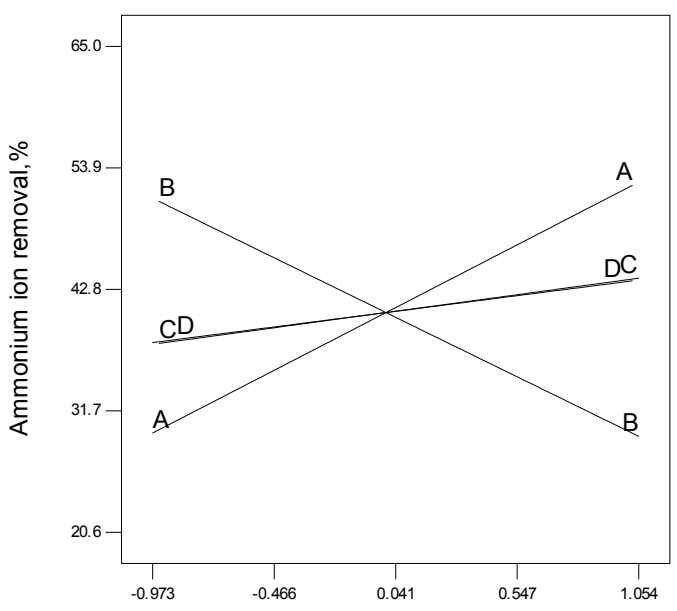

Deviation from Reference Point

Fig. 9. Perturbation plot for $\mathrm{q}_{\mathrm{e}}(\mathrm{mg} / \mathrm{g})$

\section{Conclusion}

This study has demonstrated the possibility of response surface methodology application for studying the effect of process factors on removal of $\mathrm{NH}_{4}^{+}$ions from aqueous solution by pumice granular. Based on the response surface plots, among the studied variables, pumice dosage and initial ammonium concentration significantly affected the $\mathrm{NH}_{4}^{+}$removal. The maximum $\mathrm{NH}_{4}^{+}$was modeled to be $70.3 \%$ under pumice dosage, initial $\mathrm{NH}_{4}^{+}$ion concentration, mixing rate and contact time of $100 \mathrm{~g} / 1,20 \mathrm{mg} / 1,300 \mathrm{rpm}$ and $180 \mathrm{~min}$, respectively, while the observed value was $71.4 \%$. Based on the equilibrium study, the optimum for the maximum equilibrium adsorption capacity was found to be $0.28 \mathrm{mg} / \mathrm{g}$.

\section{References}

Akbal, F. (2005) Adsorption of basic dyes from aqueous solution onto pumice powder, Journal of colloid and interface science, 286(2), pp. $455-458$

Arslan, A. \& Veli, S. (2012) Zeolite 13X for adsorption of ammonium ions from aqueous solutions and hen slaughterhouse wastewaters, Journal of the Taiwan institute of chemical engineers, 43(3), pp. 393-398.

Bandosz, T.J. \& Petit, C. (2009) On the reactive adsorption of ammonia on activated carbons modified by impregnation with inorganic compounds, Journal of colloid and interface science, 338(2), pp. 329-345.

Bardakçi, B. \& Bahçeli, S. (2010) FTIR study of modification of transition metal on zeolites for adsorption, Indian Journal of Pure \& Applied Physics, 48, pp. 615-620.

Baş, D. \& Boyac1, İ.H. (2007) Modeling and optimization I: Usability of response surface methodology Journal of Food Engineering, 78(3), pp. 836-845.
Bekaroglu, S.K., Yigit, N., Karanfil, T. \& Kitis, M. (2010) The adsorptive removal of disinfection by-product precursors in a high-SUVA water using iron oxide-coated pumice and volcanic slag particles, Journal of Hazardous Materials, 183(1), pp. 389-394.

Bolen, W.P. (2003) Pumice and pumicite. US Geological Survey Minerals Yearbook.

Box, G.E. \& Draper, N.R. (1987) Empirical model-building and response surfaces, Wiley New York 1987.

Demir, A., Gunay, A. \& Debik, E. (2002) Ammonium removal from aqueous solution by ion-exchange using packed bed natural zeolite, Water SA, 28(3), pp. 329-336.

Ersoy, B., Sariisik, A., Dikmen, S. \& Sariisik, G. (2010) Characterization of acidic pumice and determination of its electrokinetic properties in water, Powder Technology, 197(1), pp. 129-135.

Grim, R.E. (1968) Clay mineralogy. McGraw-Hill Book Company, New York, 596.

Gunduz, L., Sariisik, A., Tozacan, B., Davraz, M., Ugur, I. \& Cankiran, O. (1998) Pumice technology. Skin 1.

Karapınar, N. (2009) Application of natural zeolite for phosphorus and ammonium removal from aqueous solutions, Journal of hazardous materials, 170(2), pp. 1186-1191.

Khosravi, R., Fazlzadehdavil, M., Barikbin, B. \& Taghizadeh, A.A. (2014) Removal of hexavalent chromium from aqueous solution by granular and powdered Peganum Harmala, Applied Surface Science, 292, pp. 670-677.

Khuri, A.I. \& Cornell, J.A. (1996) Response surfaces: designs and analyses, CRC press 1996.

Kusic, H., Koprivanac, N. \& Bozic, A.L. (2011) Treatment of chlorophenols in water matrix by UV/ferrioxalate system: Part I. Key process parameter evaluation by response surface methodology, Desalination, 279(1), pp. 258-268.

Lee, K.-M. \& Gilmore, D.F. (2005) Formulation and process modeling of biopolymer (polyhydroxyalkanoates: PHAs) production from industrial wastes by novel crossed experimental design, Process Biochemistry, 40(1), pp. 229-246.

Lura, P., Bentz, D.P., Lange, D.A., Kovler, K. \& Bentur, A. (2004) Pumice aggregates for internal water curing, pp. 22-24, RILEM Publications SARL Evanston.

Mansouri, Y., Zinatizadeh, A.A., Mohammadi, P., Irandoust, M., Akhbari, A. \& Davoodi, R. (2012) Hydraulic characteristics analysis of an anaerobic rotatory biological contactor $(\mathrm{AnRBC})$ using tracer experiments and response surface methodology (RSM), Korean Journal of Chemical Engineering, 29(7), pp. 891-902.

Mason, R.L., Gunst, R.F. \& Hess, J.L. (2003) Statistical design and analysis of experiments: with applications to engineering and science, John Wiley \& Sons 2003.

Moraci, N. \& Calabrò, P.S. (2010) Heavy metals removal and hydraulic performance in zero-valent iron/pumice permeable reactive barriers, Journal of Environmental Management, 91(11), pp. 2336-2341.

Ozturk, B. \& Yildirim, Y. (2008) Investigation of sorption capacity of pumice for SO 2 capture, Process Safety and Environmental Protection, 86(1), pp. 31-36.

Panuccio, M.R., Sorgonà, A., Rizzo, M. \& Cacco, G. (2009) Cadmium adsorption on vermiculite, zeolite and pumice: batch experimental studies, Journal of Environmental Management, 90(1), pp. 364-374.

Pirsaheb, M., Dargahi, A., Hazrati, S. \& Fazlzadehdavil, M. (2014) Removal of diazinon and 2, 4-dichlorophenoxyacetic acid (2, 4-D) from aqueous solutions by granular-activated carbon, Desalination and Water Treatment, 52(22-24), pp. 4350-4355.

Vassileva, P. \& Voikova, D. (2009) Investigation on natural and pretreated Bulgarian clinoptilolite for ammonium ions removal from aqueous solutions, Journal of hazardous materials, 170(2), pp. $948-953$. 
Wang, M., Liao, L., Zhang, X., Li, Z., Xia, Z. \& Cao, W. (2011) Adsorption of low-concentration ammonium onto vermiculite from Hebei province, China, Clays and Clay Minerals, 59(5), pp. 459-465.

Yuan, L. \& Kusuda, T. (2005) Adsorption of ammonium and nitrate ions by poly ( $\mathrm{N}$-isopropylacrylamide) gel and poly
(N-isopropylacrylamide-co-chlorophyllin) gel in different states, Journal of applied polymer science, 96(6), pp. 2367-2372.

Zhu, K., Fu, H., Zhang, J., Lv, X., Tang, J. \& Xu, X. (2012) Studies on removal of $\mathrm{NH} 4+-\mathrm{N}$ from aqueous solution by using the activated carbons derived from rice husk, Biomass and bioenergy, 43, pp. 18-25. 